\title{
Fascial preadipocytes: another missing piece of the puzzle to understand fibromyalgia?
}

This article was published in the following Dove Press journal: Open Access Rheumatology: Research and Reviews

\author{
Bruno Bordoni' \\ Fabiola Marelli2,3 \\ Bruno Morabito ${ }^{2-4}$ \\ Francesca Cavallaro 5 \\ David Lintonbon ${ }^{6}$ \\ 'Foundation Don Carlo Gnocchi \\ IRCCS, Department of Cardiology, \\ Institute of Hospitalization and Care \\ with Scientific, Milan, Italy; ${ }^{2}$ CRESO, \\ School of Osteopathic Center for \\ Research and Studies, Department \\ of Fascial Osteopathic Research: \\ FORe, Gorla Minore, Italy; ${ }^{3} \mathrm{CRESO}$, \\ School of Osteopathic Center for \\ Research and Studies, Department \\ of Fascial Osteopathic Research, \\ Fano, Italy; ${ }^{4}$ Sapienza University of \\ Rome, Department of Radiological, \\ Oncological and Anatomopathological \\ Sciences, Rome, Italy; ${ }^{5}$ ICOM, \\ International College of Osteopathic \\ Medicine, Torino, Italy; ${ }^{6}$ London \\ School of Osteopathy, Department of \\ Osteopathic Technique, London, UK
}

Correspondence: Bruno Bordoni Foundation Don Carlo Gnocchi IRCCS, Department of Cardiology, Institute of Hospitalization and Care with Scientific, S Maria Nascente, Via Capecelatro 66, Milan 20100, Italy

Tel +39234963006I7

Email bordonibruno@hotmail.com

\begin{abstract}
Fibromyalgia (FM) syndrome is a chronic condition causing pain, affecting approximately $0.5 \%-6 \%$ of the developed countries' population, and on average, $2 \%$ of the worldwide population. Despite the large amount of scientific literature available, the FM etiology is still uncertain. The diagnosis is based on the clinical presentation and the severity of the symptomatology. Several studies pointed out pathological alterations within the central nervous system, suggesting that FM could originate from a central sensitization of the pain processing centers. Research supports the thesis of a peripheral neuropathic component, with the finding of axonal damages. The fibromyalgia patient has many myofascial system abnormalities, such as pain and fatigue, impairing the symptomatic profile. This paper revises the myopathic compensations, highlighting the possible role of the fascia in generating symptoms, being aware of the new information about the fascia's activity in stimulating inflammation and fat cell production.
\end{abstract}

Keywords: fibromyalgia, fascia, pain, myofascial, neuropathic pain

\section{Introduction}

Fibromyalgia (FM) syndrome is a chronic condition causing pain, affecting approximately $0.5 \%-6 \%$ of the developed countries' population, and on average, $2 \%$ of the worldwide population. ${ }^{1-3}$ Caucasian and the middle-aged females are at higher risk of FM, as well as those who have family members affected by the disorder. ${ }^{1}$

FM is characterized by various symptomatological manifestations such as widespread chronic pain (allodynia), hyperalgesia, morning stiffness, altered sensory perception (light, sounds, temperature, touch, smell), sleep disorders, mood disturbances (anxiety and depression), general fatigue, memory loss, irritable bowel, restless leg, migraine, cognitive difficulties, dysmenorrhea, and temporomandibular joint disorder. ${ }^{1-6}$

Despite the large amount of scientific literature available, FM etiology is still uncertain. The diagnosis is based on the clinical presentation and the severity of the symptomatology. ${ }^{7}$

In 2010 and 2011, the 1990 American College of Rheumatology established diagnostic criteria for the FM. The scale rating the Symptom Severity (SS) has been added to be used along with the Widespread Pain Index (WPI), while the previous routine manual exam checking the tender points' presence has been removed. ${ }^{7}$ According to the American College of Rheumatology, an FM diagnosis is based on these two scales' scores. A patient must have a WPI $\geq 7$ and an SS score $\geq 5$, or an evaluation of WPI ranging from 3 to 6 and an SS score $\geq 9.7$. The duration of the symptomatology has 
been estimated to be $\geq 3$ months without a cause justifying the pain. ${ }^{7}$ Several studies highlighted pathological alterations within the central nervous system, leading to the hypothesis that the FM could originate from a central sensitization of the pain processing centers. ${ }^{8} \mathrm{~A}$ thalamocortical dysrhythmia, due to a lower threshold for the action of calcium in the thalamus, could contribute to a constant pain processing in the cortical somatosensory system, leading to the chronicity of the disorder. ${ }^{8}$ A recent study pointed out an increase in theta oscillations within the prefrontal cortex, which could cause persistent central sensitization. ${ }^{8}$ Furthermore, another recent research demonstrated a decrease in the cortical presence of dopamine receptors, which are involved in modulating nociceptive perceptions, but further insights are needed in order to make certain assertions about the FM and the dopaminergic role. ${ }^{9}$ A study with 126 patients affected by FM recently demonstrated the presence, in some subjects, of a functional polymorphic genetic alteration, affecting the frontoparietal control network, which plays an important role in assessing and anticipating the pain sensation. ${ }^{10}$ Neurosteroids act as modulators of the synaptic transmission, facilitating or inhibiting the GABA-A receptor response, and affecting the perception of pain, mood, and cognition; the serotoninergic tone will act as a weighing needle for the neurosteroid stimulation or inhibition. An increase of neurosteroids is linked to the activation of glial cells, due to a higher concentration in mitochondrial membrane proteins; this happens in the case of chronic psychiatric and pain conditions, highlighting a cerebral inflammatory disease. ${ }^{10}$ Recent revisions still point fingers at central nervous causes. Other genetic differences (immunomodulator and purinergic, nociceptive and stress mediators, mitochondrial DNA mutation) between healthy subjects and patients affected by FM have been highlighted; the reasons are unknown. ${ }^{11,12}$ It has been documented that fibromyalgia patients have high level of central glutamate (posterior cingulate gyrus, posterior insula, ventrolateral prefrontal cortex, amygdala), which has an excitatory role on the function of neural cells, lowering the pain threshold. ${ }^{11}$ Hypotheses have been advanced about vitamin D and its role with the pain's central modulation: hypovitaminosis findings have been reported, but not in all patients. ${ }^{11}$ Magnetic resonance studies show alterations in the morphology and activity of some brain areas. Cortical white matter reduction occurs in areas (left side anterior cortex, left lateral orbitofrontal cortex) that are important for the output of the pain modulation mechanisms. ${ }^{12}$ Gray matter undergoes both a decrease in volume (superior temporal gyrus, thalamus, amygdala, periaqueductal gray, insula, putamen) and an increase in volume (orbitofrontal cortex, cerebellum, basal ganglia, cingulate cortex). ${ }^{12}$ These alterations are not fully understood. Brain activity seems to be increased especially in cerebellar areas, insula, cortical area, thalamus, and amygdala, probably explaining behavioral alterations related to the pain perception in patients with FM. ${ }^{12}$ In FM, a peripheral neuropathic component has been noticed. The epidermal nerve fibers' density is a sign of so-called "small fibrous neuropathy", a painful neuropathic disorder. ${ }^{13}$ Reduction in epidermal nerve fiber density can also occur in other conditions, such as in fibromyalgia. The origin could be immune-mediated, and it has been reported in patients affected by FM. ${ }^{13}$ The hypothesis supporting a peripheral origin of the FM is due to some data pointing to the presence of peripheral polyneuropathy (demyelinating lesions and axonopathy large nerve lesions). ${ }^{13}$ The spinal cord and brain pathway (that process sensory information) sensitivity is increased by the action of the peripheral system whose afferent nerve fibers detect noxious stimuli (C and A-delta fibers) and movement (mechanoreceptors) in patients with FM. This is probably due to the modulation of the NMDAR which, once activated thanks to the presence of glutamate and glycine, causes the depolarization of the medullary neural cells. ${ }^{14}$

The presence of peripheral neuropathy and inflammatory elements could decrease the activity-dependent slowing of $\mathrm{C}$-fibers, with a decrease in the latency time to pain, facilitating the medullary mechanism of the summation of the afferential electrical input. ${ }^{15}$ The decreased activity-dependent slowing compromises the $\mathrm{C}$-fibers activation threshold and their spontaneous activation.

The peripheral neuropathic pain could also be related to the constant activity of the spinal cordial microglia: these are immune cells of the nervous system, releasing proinflammatory substances, whose characteristics are linked to those of the macrophage cells. ${ }^{16}$ These are highly dynamic and mobile cells (minutes/seconds), characteristics that allow them to be able to repair damaged areas, under constant surveillance of the bone marrow precursor. ${ }^{16}$ The activation of microglial cells by a nerve's peripheral damage leads to a bone marrow neuroplasticity with consequent pain hypersensitivity. The damaged peripheral nervous tissue releases CSF1, linking to its glial receptor with a retrograde transport to the marrow. This will activate a membrane protein (DAP12), which will stimulate microglial genes upregulation associated with nociceptive hypersensitivity (Irf8 and Irf5), neuropathic pain, allodynia, and myalgia. ${ }^{16-18}$ The fibromyalgia patient is characterized by peripheral abnormalities affecting the myofascial system. ${ }^{2,19}$ It is known that in some chronic 
conditions, such as congestive heart failure (CHF) and airway obstruction (chronic obstructive pulmonary disease), there is no clear correlation between the clinical presentation and the instrumental evaluation (echocardiography and spirometry, respectively). It is the myopathic chronic adaptation, with the visceral disease as a background, that highly impairs the symptomatology, such as dyspnea, fatigue, and pain. ${ }^{20,21}$ This paper explains the myopathic adaptations in the fibromyalgia patient, highlighting the possible contribution of the fascia to the fibromyalgia's symptomatology, being aware of the new information about the fascial role in the production of fat and inflammatory cells.

\section{Myofascial system's compensation in patients with FM}

The fascial tissue is equally distributed throughout the entire body, creating various layers at different depths and forming a three-dimensional metabolic and mechanical matrix. The following four fascial planes can be distinguished: the superficial fascia, the axial/appendicular fascia or myofascia, the meningeal fascia, and the visceral fascia. ${ }^{22}$ The myofascial continuum, the axial fascia, extends in depth through the body, surrounding the contractile areas, the vessels, and the nerves. This fascia includes the epimysium, perimysium and endomysium, the periosteum, the tissue covering tendons and ligaments, as well as joint capsules. ${ }^{22}$ Muscle tissue is an integral part of the fascial system (myofascial), having the same embryonic origin. ${ }^{21}$ DNA fragmentations can be noticed within the muscle fibers, without apoptotic signs or obvious evidence of inflammatory processes. ${ }^{23-27}$ Type I fibers (slow) are more likely to be lysed and consumed, while atrophy processes frequently occur within the Type II (fast) fibers. ${ }^{23,24,27-30}$ Anomalous lipid, subsarcolemmal glycogen deposits, and lipofuscin are found within the contractile fibers..$^{23,29,31,32}$ The latter is considered to be one of the aging pigments, as it is formed by the oxidative degradation, and is known to be inversely proportional to longevity. ${ }^{33}$ Mitochondrial function is altered along with morphological (wider) and functional changes; aerobic metabolism seems to be deficient in both building up and using energy. ${ }^{23,31}$ There is a reduction in phosphate production, both under strain and at rest. ${ }^{23,24,34}$ There is an unbalanced relationship between inorganic phosphorus production and the presence of ATP, indicating one of the possible causes of muscular fatigue. ${ }^{35}$ In the case of excessive inorganic phosphorus levels, the phosphate binds with calcium favoring an inorganic phosphate precipitation, which in turn prevents the fundamental link with the actin for the muscular contraction to take place, as a result of the cross-bridge cycle. ${ }^{36}$ There seems to be a greater use of anaerobic muscle metabolism, probably due to a dysregulation of the vasoconstrictive mechanism, along with hypoperfusion occurring within the fibers. ${ }^{27,37}$ There are vasospasms of the capillary architecture, causing low levels of constant ischemia and low levels of oxygen release to the contractile cell. ${ }^{31,38-40}$ Often, the endothelial cells are swollen and disorganized, with a greater thickness and a lower permeability. ${ }^{31}$ The capillary density, ie, the number of capillaries per area and per square millimeter, is decreased as a result. ${ }^{28,41}$ The blood flow to the muscle cells is reduced, both at rest and in activity. ${ }^{38}$

This ischemia, though of low magnitude, may relate to the phenomenon of pain and altered nociceptive perception. The vascular hypoperfusion stimulates greater local production of iNOS, an enzyme involved in the synthesis of NO. ${ }^{42,43}$ In proper dosage, it is essential for muscle regeneration and perfusion, but NO's abnormal quantities can lead to cellular oxidative stress. ${ }^{43}$ The oxidative stress, due to an overload of free radicals within the system, damages the structural integrity of the fiber. ${ }^{42}$ The nociceptive pain perception also occurs as a result of a constant ischemia-reperfusion, related to the activity of ASIC3 that is involved in type III and IV somatosensory afferents (mechanosensitive component), as well as the presence of lactate and protons within the muscles. ${ }^{44,45}$ Latent ischemia seems to produce an inflammatory systemic response allowing IL-1 $\beta$ cytokine to activate its receptor on III/IV (IL-1r1), thus increasing ASIC3's expression. This cascade of events, probably through the use of JNK pathway, would modulate myalgic afferent impulse activity, resulting in a lower pain threshold. ${ }^{44}$ There are alterations in the connective tissue metabolism, although it is not yet possible to find out about the causes. ${ }^{46}$ According to some studies, a decrease in the density of perimysium and endomysium, along with a build-up of connective tissue on the nerve pathways crossing the muscles, has been hypothesized. ${ }^{47,48}$ This fascial remodeling could alter the muscles afferent-related response, reducing pain perception. ${ }^{48}$

The electrical activity of motor neurons seems to be altered, due to a higher electric conductivity that coordinates the contraction of the muscle. ${ }^{27}$ As a result, the nerve undergoes morphological remodeling superficially. A less dense lamellar structure is pointed out within the perineurium and endoneurium (fascial tissue), along with functional alterations. ${ }^{49}$ If the nerve sliding through soft tissues, such as muscles, is impaired because of myofascial stiffness or restriction (eg, in case of remodeling muscle tissue), nervi nervorum are activated, triggering movement-related pain. ${ }^{50}$ They play a fundamental role in regulating the metabolic nerve background. ${ }^{51}$ If a nerve runs into an inflamed area, 
such as muscle fibers, despite the fact that its nociceptors are intact, the axon may get inflamed and more sensitive to mechanical variations, causing pain. ${ }^{51}$ The fascia is not just about contractile bundles' subdivision or the attachment to bones, but everything that surrounds the perimysium, thus connecting every part of the body. One needs only to consider the lumbar fascia or the several fascicles favoring the muscles' tension transmission to the whole body. ${ }^{52}$ This fascial continuum is crucial for proper motor coordination and the final movement to take place. ${ }^{52,53}$ Everyday movements of the body are possible thanks to the presence of the fascial tissues and their inseparable interconnection, which allows the sliding of the muscular framework and the sliding of nerves and vessels between/around contractile fields and joints, the same way all the organs can slide and move among each other, influenced by the position of the body (Figure 1). An alteration of the bodily movements would have a negative influence on neural, peripheral, and central processes, which would induce modifications in the motor patterns. ${ }^{52}$ An alteration of the function and structure of the lumbar fascia could cause disturbances to the whole back, shoulders, neck, and motor imbalances of the muscular area of the abdomen and thorax. ${ }^{52}$

The fascial changes that have been recorded in several studies are thought to be among the causes of muscular incoordination observed in patients with FM. ${ }^{54-56}$

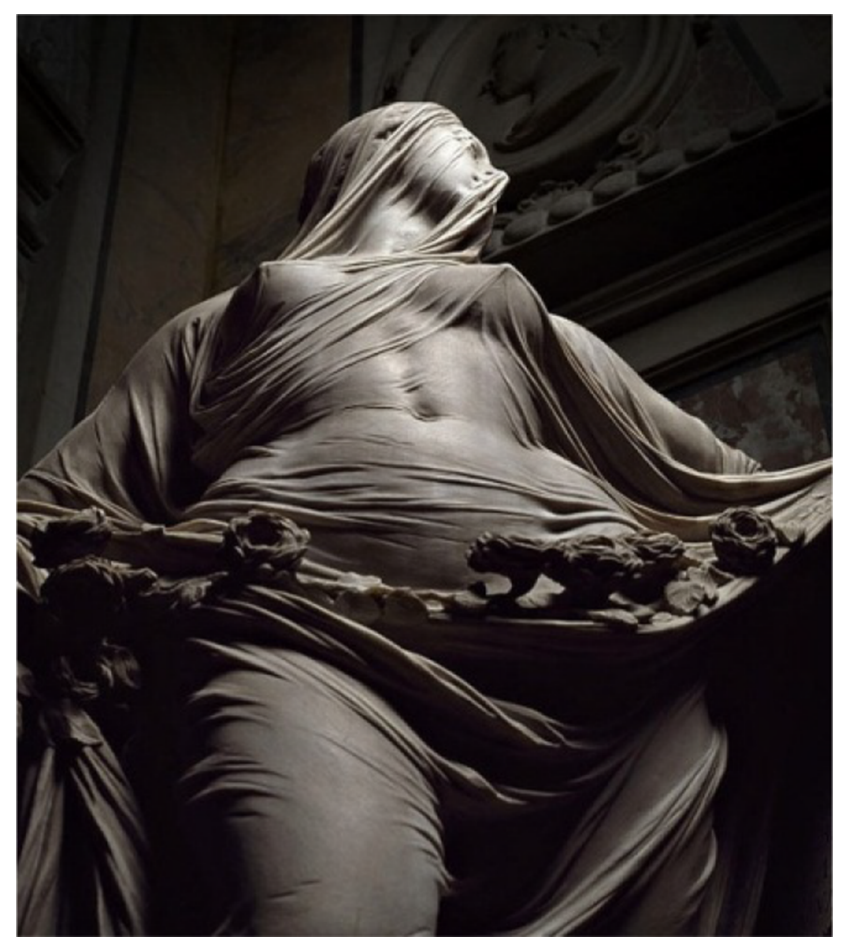

Figure I Sculpture of veiled woman by Antonio Corradini, 1668-1752.

Note: We can imagine this baroque representation as the action of dysfunctional fascial tissue impairing the patient's proper muscular activation and functionality.

\section{Adipocytes and fascia}

A lot of scientific evidence has shown an existing link between FM patients and overweight/obesity, with an average of approximately $30 \%$ and $40 \%$, respectively. ${ }^{57}$ Possible causes could be related to sleep disorders, cognitive and behavioral disorders, and/or decreased physical activity. All these reasons do not necessarily concern the total calorie intake or the diet quality. ${ }^{57,58}$ It has been shown that there is an increase in intramuscular adiposity, probably due to decreased mitochondrial density and function, along with disorders of the hypothalamic-pituitary-adrenal axis. ${ }^{59}$ Body fat composition seems to influence a higher level of nociceptive factors as well as a low but constant inflammatory status. ${ }^{59}$ Adipose tissue secretes proinflammatory cytokines, playing a role in generating and perpetuating pain in FM. ${ }^{60,61}$ Adipose tissue is composed of adipocytes embedded in the loose connective tissue, preadipocytes, and immune cells; it is innervated and vascularized. ${ }^{62}$ Adipocytes have the ability to secrete different cytokines, including high molecular weight adipokines. The latter stimulate inflammation along with increase in IL-6 levels. ${ }^{62}$ The hormone leptin, secreted by the adipose tissue, is responsible for weight gain and inflammatory stuatus. ${ }^{62}$ Adipose tissue also secretes chemokines, being stimulated by an already existing inflammatory process, thus contributing to perpetuation of the event. ${ }^{61}$ Their function is to manage leukocyte traffic through the interaction with specific seventransmembrane-spanning $\mathrm{G}$ protein-coupled receptors that are involved in development, inflammation and cancer. ${ }^{63}$

The corticotropin-releasing factor (CRF) is secreted by the central nervous system, released by the hypothalamus' neurons, with the ability to reach peripheral tissues through the sensory afferent nerve fibers. This neuropeptide binds to the immune cells expressing its receptors (CRF1R and CRF2R) such as macrophages, neutrophils, mast cells, monocytes, and other cell types. ${ }^{64,65}$ This system is also seen in the adipose tissue where CRF could play a role in the development of a constant but low-level inflammation and contribute to peripheral pain modulation. ${ }^{65}$ Adipocytes are thought to originate from four tissues: stromal vascular cells, pericytes, adipose tissue endothelial cells, and/or hematopoietic stem cells within the bone marrow. ${ }^{66}$ Recently, the ability to synthesize adipose tissue starting from the superficial subcutaneous fascial system has been discovered in animals ${ }^{67}$ Fascial preadipocytes are unable to be converted into other cell types (myocytes or osteocytes), but they end up differentiating into adipose cells. ${ }^{67}$ In the rat's superficial fascial tissue, there is a parallel growth of fat (adipogenesis) and vascular pathways feeding the adipocytes 
(angiogenesis). ${ }^{67}$ In the future, many questions will have to be answered. Does the adipose superficial fascia influence the inflammatory status? Can the fascial system as a whole (superficial and deep, somatic, visceral, and meningeal) stimulate adipogenesis and inflammation? Does the fascial adipose tissue influence FM symptomatology?

\section{Conclusion}

It is known that there is central sensitization and peripheral neurological alterations with FM. Evidences link fibromyalgia with overweight/obesity, which is associated with greater peripheral pain perception. Recently, in animal models, the adipogenic capacity of the subcutaneous superficial fascia has been uncovered. This paper discussed the possible involvement of the fascial system in this chronic pathology. The fascial system can produce inflammatory substances which could negatively influence the inflammatory environment. New questions are now opening up about the fascial continuum as a whole, whether it is capable of producing adipocytes, and whether this contributes to the painful symptomatology in patients affected by FM.

\section{Disclosure}

The authors report no conflicts of interest in this work.

\section{References}

1. Feinberg T, Sambamoorthi U, Lilly C, Innes KK. Potential mediators between fibromyalgia and C-reactive protein: results from a Large U.S. Community Survey. BMC Musculoskelet Disord. 2017;18(1):294.

2. Favero G, Trapletti V, Bonomini F, et al. Oral supplementation of melatonin protects against fibromyalgia-related skeletal muscle alterations in reserpine-induced myalgia rats. Int J Mol Sci. 2017;18(7):pii:E1389.

3. Bäckryd E, Tanum L, Lind AL, Larsson A, Gordh T. Evidence of both systemic inflammation and neuroinflammation in fibromyalgia patients, as assessed by a multiplex protein panel applied to the cerebrospinal fluid and to plasma. $J$ Pain Res. 2017;10:515-525.

4. Kosek E, Altawil R, Kadetoff D, et al. Evidence of different mediators of central inflammation in dysfunctional and inflammatory pain--interleukin- 8 in fibromyalgia and interleukin- $1 \beta$ in rheumatoid arthritis. J Neuroimmunol. 2015;280:49-55.

5. Ablin J, Neumann L, Buskila D. Pathogenesis of fibromyalgia - a review. Joint Bone Spine. 2008;75(3):273-279.

6. Sayılır S, Çullu N. Decreased olfactory bulb volumes in patients with fibromyalgia syndrome. Clin Rheumatol. 2017;36(12):2821-2824.

7. Taylor AG, Fischer-White TG, Anderson JG, et al. Stress, Inflammation and pain: a potential role for monocytes in fibromyalgia-related symptom severity. Stress Health. 2016;32(5):503-513.

8. Fallon N, Chiu Y, Nurmikko T, Stancak A. Altered theta oscillations in resting EEG of fibromyalgia syndrome patients. Eur J Pain. 2018;22(1):49-57.

9. Albrecht DS, MacKie PJ, Kareken DA, et al. Differential dopamine function in fibromyalgia. Brain Imaging Behav. 2016;10(3):829-839.

10. Kosek E, Martinsen S, Gerdle B, et al. The translocator protein gene is associated with symptom severity and cerebral pain processing in fibromyalgia. Brain Behav Immun. 2016;58:218-227.

11. Talotta R, Bazzichi L, Di Franco M, et al. One year in review 2017: fibromyalgia. Clin Exp Rheumatol. 2017;35 Suppl 105(3):6-12.
12. Sawaddiruk P, Paiboonworachat S, Chattipakorn N, Chattipakorn SC. Alterations of brain activity in fibromyalgia patients. J Clin Neurosci. 2017;38:13-22.

13. Caro XJ, Winter EF. The role and importance of small fiber neuropathy in fibromyalgia pain. Curr Pain Headache Rep. 2015;19(12):55.

14. Littlejohn G, Guymer E. Modulation of NMDA receptor activity in fibromyalgia. Biomedicines. 2017;5(2):15.

15. Dickie AC, McCormick B, Lukito V, Wilson KL, Torsney C. Inflammatory pain reduces $\mathrm{c}$ fiber activity-dependent slowing in a sex-dependent manner, amplifying nociceptive input to the spinal cord. $J$ Neurosci. 2017;37(27):6488-6502.

16. Mapplebeck JC, Beggs S, Salter MW. Molecules in pain and sex: a developing story. Mol Brain. 2017;10(1):9.

17. Gao YJ, Ji RR. Chemokines, neuronal-glial interactions, and central processing of neuropathic pain. Pharmacol Ther. 2010;126(1):56-68.

18. Yasui M, Yoshimura T, Takeuchi S, et al. A chronic fatigue syndrome model demonstrates mechanical allodynia and muscular hyperalgesia via spinal microglial activation. Glia. 2014;62(9):1407-1417.

19. Liptan GL. Fascia: a missing link in our understanding of the pathology of fibromyalgia. J Bodyw Mov Ther. 2010;14(1):3-12.

20. Bordoni B, Marelli F, Morabito B, Sacconi B. Manual evaluation of the diaphragm muscle. Int J Chron Obstruct Pulmon Dis. 2016;11:1949-1956.

21. Bordoni B, Marelli F. The fascial system and exercise intolerance in patients with chronic heart failure: hypothesis of osteopathic treatment. J Multidiscip Healthc. 2015;8:489-494.

22. Bordoni B, Marelli F, Morabito B, Sacconi B. The indeterminable resilience of the fascial system. J Integr Med. 2017;15(5):337-343.

23. Sprott H, Salemi S, Gay RE, et al. Increased DNA fragmentation and ultrastructural changes in fibromyalgic muscle fibres. Ann Rheum Dis. 2004;63(3):245-251.

24. Staud R, Rodriguez ME. Mechanisms of disease: pain in fibromyalgia syndrome. Nat Clin Pract Rheumatol. 2006;2(2):90-98.

25. Banic B, Petersen-Felix S, Andersen OK, et al. Evidence for spinal cord hypersensitivity in chronic pain after whiplash injury and in fibromyalgia. Pain. 2004;107(1-2):7-15.

26. Flodgren GM, Crenshaw AG, Alfredson H, et al. Glutamate and prostaglandin E2 in the trapezius muscle of female subjects with chronic muscle pain and controls determined by microdialysis. Eur $J$ Pain. 2005;9(5):511-515.

27. Gerdle B, Ostlund N, Grönlund C, Roeleveld K, Karlsson JS. Firing rate and conduction velocity of single motor units in the trapezius muscle in fibromyalgia patients and healthy controls. J Electromyogr Kinesiol. 2008;18(5):707-716.

28. Bengtsson A. The muscle in fibromyalgia. Rheumatology (Oxford). 2002;41(7):721-724.

29. Pongratz DE, Späth M. Morphologic aspects of fibromyalgia. Z Rheumatol. 1998;57 (Suppl 2):47-51.

30. Yunus MB, Kalyan-Raman UP, Kalyan-Raman K, Masi AT. Pathologic changes in muscle in primary fibromyalgia syndrome. Am J Med. 1986;81(3A):38-42.

31. Le Goff P. Is fibromyalgia a muscle disorder? Joint Bone Spine. 2006;73(3):239-242.

32. Yunus MB, Kalyan-Raman UP, Masi AT, Aldag JC. Electron microscopic studies of muscle biopsy in primary fibromyalgia syndrome: a controlled and blinded study. J Rheumatol. 1989;16(1):97-101.

33. Nakae Y, Stoward PJ, Kashiyama T, et al. Early onset of lipofuscin accumulation in dystrophin-deficient skeletal muscles of DMD patients and mdx mice. J Mol Histol. 2004;35(5):489-499.

34. Vøllestad NK, Mengshoel AM. Relationships between neuromuscular functioning, disability and pain in fibromyalgia. Disabil Rehabil. 2005;27(12):667-673.

35. Sprott H, Rzanny R, Reichenbach JR, Kaiser WA, Hein G, Stein G. 31P magnetic resonance spectroscopy in fibromyalgic muscle. Rheumatology (Oxford). 2000;39(10):1121-1125.

36. Fitts RH. The cross-bridge cycle and skeletal muscle fatigue. $J$ Appl Physiol (1985). 2008;104(2):551-558. 
37. Katz DL, Greene L, Ali A, Faridi Z. The pain of fibromyalgia syndrome is due to muscle hypoperfusion induced by regional vasomotor dysregulation. Med Hypotheses. 2007;69(3):517-525.

38. Elvin A, Siösteen AK, Nilsson A, Kosek E. Decreased muscle blood flow in fibromyalgia patients during standardised muscle exercise: a contrast media enhanced colour Doppler study. Eur J Pain. 2006;10(2):137-144.

39. Morf S, Amann-Vesti B, Forster A, et al. Microcirculation abnormalities in patients with fibromyalgia - measured by capillary microscopy and laser fluxmetry. Arthritis Res Ther. 2005;7(2):R209-R216.

40. Srikuea R, Symons TB, Long DE, et al. Association of fibromyalgia with altered skeletal muscle characteristics which may contribute to postexertional fatigue in postmenopausal women. Arthritis Rheum. 2013;65(2):519-528.

41. Lindh M, Johansson G, Hedberg M, Henning GB, Grimby G. Muscle fiber characteristics, capillaries and enzymes in patients with fibromyalgia and controls. Scand J Rheumatol. 1995;24(1):34-37.

42. Kasikcioglu E, Dinler M, Berker E. Reduced tolerance of exercise in fibromyalgia may be a consequence of impaired microcirculation initiated by deficient action of nitric oxide. Med Hypotheses. 2006;66(5):950-952.

43. McIver KL, Evans C, Kraus RM, Ispas L, Sciotti VM, Hickner RC. NO-mediated alterations in skeletal muscle nutritive blood flow and lactate metabolism in fibromyalgia. Pain. 2006;120(1-2):161-169.

44. Ross JL, Queme LF, Cohen ER, et al. Muscle IL1 $\beta$ drives ischemic myalgia via ASIC3-mediated sensory neuron sensitization. J Neurosci. 2016;36(26):6857-6871.

45. Queme LF, Ross JL, Lu P, Hudgins RC, Jankowski MP. Dual modulation of nociception and cardiovascular reflexes during peripheral ischemia through P2Y1 receptor-dependent sensitization of muscle afferents. $J$ Neurosci. 2016;36(1):19-30.

46. Ribel-Madsen S, Christgau S, Gronemann ST, Bartels EM, DanneskioldSamsøe B, Bliddal H. Urinary markers of altered collagen metabolism in fibromyalgia patients. Scand J Rheumatol. 2007;36(6):470-477.

47. Gronemann ST, Ribel-Madsen S, Bartels EM, Danneskiold-Samsoe $\mathrm{B}$, Bliddal $\mathrm{H}$. Collagen and muscle pathology in fibromyalgia patients. Rheumatology (Oxford). 2004;43(1):27-31.

48. Sprott H, Müller A, Heine H. Collagen crosslinks in fibromyalgia. Arthritis Rheum. 1997;40(8):1450-1454.

49. Ribel-Madsen S, Gronemann ST, Bartels EM, Danneskiold-Samsøe B, Bliddal H. Collagen structure in skin from fibromyalgia patients. Int $J$ Tissue React. 2005;27(3):75-82.

50. Bordoni B, Bordoni G. Reflections on osteopathic fascia treatment in the peripheral nervous system. J Pain Res. 2015;8:735-740.

51. Bove GM. Epi-perineurial anatomy, innervation, and axonal nociceptive mechanisms. J Bodyw Mov Ther. 2008;12(3):185-190.

52. Bordoni B, Zanier E. Clinical and symptomatological reflections: the fascial system. J Multidiscip Healthc. 2014;7:401-411.
53. Choi HW, Kim YE. Effect of lumbar fasciae on the stability of the lower lumbar spine. Comput Methods Biomech Biomed Engin. 2017; 20(13):1431-1437.

54. Pérez-de-Heredia-Torres M, Huertas-Hoyas E, Martínez-Piédrola R, et al. Balance deficiencies in women with fibromyalgia assessed using computerised dynamic posturography: a cross-sectional study in Spain. BMJ Open. 2017;7(7):e016239.

55. Heredia-Jimenez J, Orantes-Gonzalez E, Soto-Hermoso VM. Variability of gait, bilateral coordination, and asymmetry in women with fibromyalgia. Gait Posture. 2016;45:41-44.

56. Muto LH, Sauer JF, Yuan SL, Sousa A, Mango PC, Marques AP. Postural control and balance self-efficacy in women with fibromyalgia: are there differences? Eur J Phys Rehabil Med. 2015;51(2):149-154.

57. de Araújo TA, Mota MC, Crispim CA. Obesity and sleepiness in women with fibromyalgia. Rheumatol Int. 2015;35(2):281-287.

58. Slim M, Calandre EP, Garcia-Leiva JM, et al. The effects of a gluten-free diet versus a hypocaloric diet among patients with fibromyalgia experiencing gluten sensitivity-like symptoms: a pilot, openlabel randomized clinical trial. J Clin Gastroenterol. 2017;51(6): 500-507.

59. Gerdle B, Forsgren MF, Bengtsson A, et al. Decreased muscle concentrations of ATP and PCR in the quadriceps muscle of fibromyalgia patients - a 31P-MRS study. Eur J Pain. 2013;17(8):1205-1215.

60. Sluka KA, Clauw DJ. Neurobiology of fibromyalgia and chronic widespread pain. Neuroscience. 2016;338:114-129.

61. Ignacio RM, Gibbs CR, Lee ES, Son DS. Differential chemokine signature between human preadipocytes and adipocytes. Immune Netw. 2016;16(3):189-194.

62. Peterlin BL, Sacco S, Bernecker C, Scher AI. Adipokines and migraine: a systematic review. Headache. 2016;56(4):622-644.

63. Kabir SM, Lee ES, Son DS. Chemokine network during adipogenesis in 3T3-L1 cells: differential response between growth and proinflammatory factor in preadipocytes vs. adipocytes. Adipocyte. 2014;3(2):97-106.

64. Kempuraj D, Thangavel R, Selvakumar GP, et al. Brain and peripheral atypical inflammatory mediators potentiate neuroinflammation and neurodegeneration. Front Cell Neurosci. 2017;11:216.

65. Dermitzaki E, Venihaki M, Tsatsani C, et al. The multi-faceted profile of Corticotropin-Releasing Factor (CRF) family of neuropeptides and of their receptors on the paracrine/local regulation of the inflammatory response. Curr Mol Pharmacol. 2018;11(1):39-50.

66. Cawthorn WP, Scheller EL, MacDougald OA. Adipose tissue stem cells meet preadipocyte commitment: going back to the future. $J$ Lipid Res. 2012;53(2):227-246.

67. Su X, Lyu Y, Wang W, et al. Fascia origin of adipose cells. Stem Cells. 2016;34(5):1407-1419.
Open Access Rheumatology: Research and Reviews

\section{Publish your work in this journal}

Open Access Rheumatology: Research and Reviews is an international, peerreviewed, open access journal publishing original research, reports, editorials, reviews and commentaries on all aspects of clinical and experimental rheumatology in the clinic and laboratory including the following topics: Pathology, pathophysiology of rheumatological diseases; Investigation, treatment and

\section{Dovepress}

management of rheumatological diseases; Clinical trials and novel pharmacologi$\mathrm{cal}$ approaches for the treatment of rheumatological disorders. The manuscript management system is completely online and includes a very quick and fai peer-review system, which is all easy to use. Visit http://www.dovepress.com/ testimonials.php to read real quotes from published authors. 